\title{
Investigation of thermal, moisture, and mechanical properties of wet and dry fired clay materials to assess frost damage risk
}

\author{
Kazuma Fukui ${ }^{1, *}$, Chiemi Iba $^{1}$, Madoka Taniguchi ${ }^{2}$, Kouichi Takahashi ${ }^{2}$, \\ and Daisuke Ogura ${ }^{1}$ \\ ${ }^{1}$ Kyoto University, Graduate School of Engineering, 615-8540 Kyoto, Japan \\ ${ }^{2}$ Hokkaido Research Organization, 078-8801 Asahikawa, Japan
}

\begin{abstract}
Frost action is one of the main causes for deterioration of porous building materials under defined hygrothermal conditions. For an accurate assessment of the frost damage risk under various environmental conditions, thermal, moisture, and mechanical properties should be considered; the hygrothermal properties affect the distribution of temperature and amount of frozen water in the material, whereas the mechanical properties are necessary to predict deformation and damage. Moreover, the dependency of these properties on the moisture content should be understood. Therefore, in this study, thermal, moisture, and mechanical properties of wet and dry fired clay materials were measured. The fired clay materials were sintered at two different temperatures, $1000{ }^{\circ} \mathrm{C}$ and $1100{ }^{\circ} \mathrm{C}$ (samples $\mathrm{T} 10$ and T11, respectively) for comparison. The measured thermal and mechanical properties are considerably different in the wet state compared to the dry state. Freeze-thaw tests were conducted to investigate the relation between the material properties and the frost resistance under a simple experimental condition. As expected, based on the pore structure and obtained mechanical properties, T10 exhibited lower frost resistance than T11 in the freeze-thaw test. Finally, frost damage risk was assessed under various environmental conditions based on the obtained hygrothermal and mechanical properties.
\end{abstract}

\section{Introduction}

Frost action is one of the major deteriorating agents for porous building materials under defined hygrothermal conditions. Therefore, an accurate prediction of the frost damage risk under various environmental conditions is necessary for investigating the causes of deterioration, choosing suitable building materials, and proposing effective building construction and repair methods. Like cement-based materials, fired clay materials are sensitive to frost action. Therefore, several researchers investigated their frost resistance and damage mechanisms. For example, some studies investigated the relation between pore

\footnotetext{
* Corresponding author: be.fukui-k1820@archi.kyoto-u.ac.jp
} 
structure and frost resistance [1, 2], whereas some focused on the dominant damage mechanism of fired clay materials [3, 4]. Wardeh and Perrin [5] observed the deformation of roof tiles during freezing-thawing cycles and investigated deformation mechanisms. Iba et al. [6] conducted field surveys on roof tiles and suggested typical damage mechanisms caused by freezing.

Numerous studies have been done on the properties of fired clay materials, such as thermal conductivity [7], water absorption [8-10], compressive strength [9-11], and bending strength $[8,9]$. However, to the best of our knowledge, no study has adequately examined all the thermal, moisture, and mechanical properties of fired clay materials. The hygrothermal properties affect the distribution of temperature and amount of frozen water in the material, whereas the mechanical properties are necessary to predict deformation and damage. Therefore, they should be considered when assessing frost damage risk under actual weather conditions. Moreover, the dependency of these properties on the moisture content should be understood.

To adequately address the risk of frost damage, the thermal conductivity, water vapor permeability, moisture diffusivity, adsorption isotherm, tensile strength, and fracture toughness of the fired clay materials in wet and dry conditions are examined herein. Additionally, we also conducted freeze-thaw tests on the materials to compare the material properties and the frost resistance under a simple experimental condition. Finally, we assess frost damage risk under various environmental conditions based on the measured hygrothermal and mechanical properties.

\section{Materials and Methods}

\subsection{Materials}

Clay produced in Aichi Prefecture was chosen because it is commonly used to manufacture roof files. The clay was sintered at two different temperatures, $1000{ }^{\circ} \mathrm{C}$ and $1100{ }^{\circ} \mathrm{C}$ (samples T10 and T11, respectively) to compare the material properties and frost damage risk. The log differential pore volume distribution measured using mercury intrusion porosimetry and freezing point as a function of pore diameter (as given in Ref. [12]) are displayed in Fig. 1; T10 contained narrower pores than T11; thus, most of the absorbed water in T10 is expected to freeze at a lower temperature than that in T11.

The dry density, water content at capillary saturation $w_{c}$, and water content at vacuum saturation $w_{v}$ were correspondingly determined to be $1800\left[\mathrm{~kg} / \mathrm{m}^{3}\right], 287\left[\mathrm{~kg} / \mathrm{m}^{3}\right]$, and 299 $\left[\mathrm{kg} / \mathrm{m}^{3}\right]$ in the case of T10 and $1960\left[\mathrm{~kg} / \mathrm{m}^{3}\right], 193\left[\mathrm{~kg} / \mathrm{m}^{3}\right]$, and $215\left[\mathrm{~kg} / \mathrm{m}^{3}\right]$ in the case of T11.

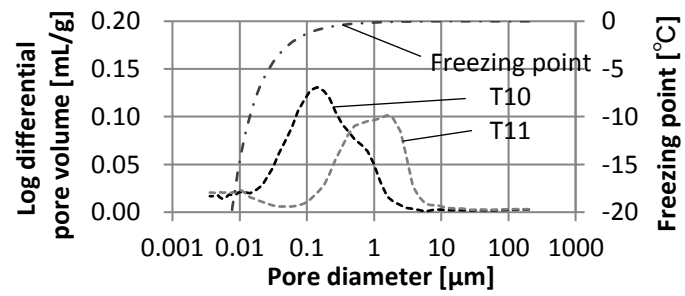

Fig. 1. Pore size distribution of T10 and T11 and the freezing point as a function of pore diameter. 


\subsection{Methods}

\subsubsection{Thermal and moisture properties}

The measured hygrothermal properties included the thermal conductivity $\lambda$, water vapor permeability $\lambda$, moisture diffusivity $D$, and adsorption isotherm (AI). The specimens comprising a thickness of approximately $20 \mathrm{~mm}$ and corresponding surface area of approximately $90 \mathrm{~mm} \times 300 \mathrm{~mm}, 90 \mathrm{~mm} \times 90 \mathrm{~mm}$, and $90 \mathrm{~mm} \times 45 \mathrm{~mm}$ were used in the measurements of $\lambda, \lambda$, and $D$. These measurements were made in a laboratory where the temperature was controlled at $23{ }^{\circ} \mathrm{C}$ by an air conditioner.

The $\lambda$ of air-dried and wet specimens was first measured at three places on one of the $90 \mathrm{~mm} \times 300 \mathrm{~mm}$ surfaces using the transient hot wire method (referring to ISO 8894-2 [13]). Notably, the wet specimens were covered with plastic wrap to prevent evaporation after $12 \mathrm{~h}$ of water absorption.

The cup method was used to obtain $\lambda$ '. The surfaces other than the test area, which was a rectangular section of $80 \mathrm{~mm} \times 80 \mathrm{~mm}$, were sealed with epoxy resin and aluminum foil. The gap between the cup and specimen was sealed with paraffin. The relative humidity $(\mathrm{RH})$ in the cup was maintained at $85 \%$ and the cup was put in a test chamber with $53 \% \mathrm{RH}$. Free water uptake experiments were then completed to obtain $D$ [14]. One side of a specimen with the surface area of $20 \mathrm{~mm} \times 45 \mathrm{~mm}$ was chosen as a water absorption surface and the surfaces other than the $20 \mathrm{~mm} \times 45 \mathrm{~mm}$ surfaces were sealed with epoxy resin and aluminum foil. The mass of the specimen was measured several times during the experiments, and the water absorption coefficient $A\left[\mathrm{~kg} /\left(\mathrm{m}^{2} \cdot \mathrm{s}^{1 / 2}\right)\right]$ was determined from the slope of the mass as a function of the square root of the elapsed time. Equation (1) was then used to calculate $D\left[\mathrm{~m}^{2} / \mathrm{s}\right][14]$.

$$
D \approx\left(A / w_{c}\right)^{2}
$$

Notably, $D$ is an averaged value under unsaturated condition.

The gas (water vapor) adsorption method was used to obtain the AI with Belsorp Max manufactured by MicrotracBEL Corp., Japan. The materials were broken into small pieces before AI measurements ( $0.196 \mathrm{~g}$ and $0.222 \mathrm{~g}$ specimens from $\mathrm{T} 10$ and $\mathrm{T} 11$, respectively), and the measurements were performed at $25^{\circ} \mathrm{C}$.

\subsubsection{Mechanical properties}

The tensile strength $\sigma$ and stress intensity factor $K_{I C}$, an index of the fracture toughness, were measured using air-dried and vacuum-saturated specimens. Three and five specimens were prepared for the $\sigma$ and $K_{I C}$ measurements, respectively; each had dimensions of approximately $40 \mathrm{~mm} \times 40 \mathrm{~mm} \times 20 \mathrm{~mm}$ and $8 \mathrm{~mm} \times 6 \mathrm{~mm} \times 80 \mathrm{~mm}$, respectively. The measurements were performed in a laboratory where the temperature was maintained at $20{ }^{\circ} \mathrm{C}$ by an air conditioner.

Before the $\sigma$ measurements, the $40 \mathrm{~mm} \times 40 \mathrm{~mm}$ surfaces were bonded to jigs with epoxy resin. Following this procedure, the specimens were pulled in the thickness direction. Although the load was controlled in the measurements using the air-dried T10, the displacement was controlled in the other measurements to avoid applying a heavy load to the measurement system. The rate of load change was $1[\mathrm{kN} / \mathrm{min}]$ (corresponding to approximately $0.10-0.15[\mathrm{~mm} / \mathrm{min}]$, and the rate of displacement change was $0.5[\mathrm{~mm} / \mathrm{min}]$.

Further, the $K_{I C}$ was measured based on JIS R 1668 [15]; a schematic of the test is illustrated in Fig. 2. A $0.5-\mathrm{mm}$ wide and 1.9-2.9-mm deep notch was made on the center 
line of one of the $80 \mathrm{~mm} \times 6 \mathrm{~mm}$ surfaces. Four point-bending tests were conducted. During the experiments, the rate of displacement change was controlled at $0.5[\mathrm{~mm} / \mathrm{min}]$. From these results, $K_{I C}\left[\mathrm{MPa} \cdot \mathrm{m}^{1 / 2}\right]$ was calculated as shown in Equation (2).

$$
\begin{gathered}
K_{I C}=\frac{3 P_{\max }(L-l)}{2 w h^{2}} \sqrt{\pi a} F\left(\frac{a}{h}\right) \\
F\left(\frac{a}{h}\right)=\sqrt{\frac{2 h}{\pi a} \tan \left(\frac{\pi a}{2 h}\right)} \times \frac{0.923+0.199(1-\sin (\pi a / 2 h))^{4}}{\cos (\pi a / 2 h)},
\end{gathered}
$$

where $P_{\max }$ is the maximum load [N], $a$ is the depth of the notches [mm], and $F$ is a correction factor. The other symbols are shown in Fig. 2.

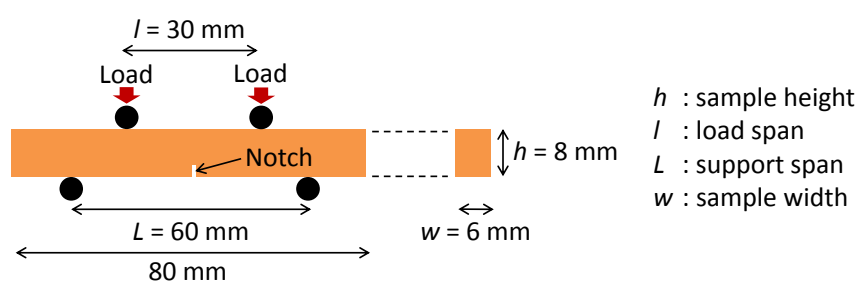

Fig. 2. Schematic of the stress intensity factor measurement based on Ref. 15.

\subsubsection{Freeze-thaw test}

Freeze-thaw (FT) tests were conducted according to Procedure B, Rapid Freezing in Air and Thawing in Water, of ASTM C 666 [16]. Four specimens (approximately $300 \mathrm{~mm} \times 90$ $\mathrm{mm} \times 20 \mathrm{~mm}$ ) were prepared, for both T10 and T11. After $48 \mathrm{~h}$ of water absorption, the specimens were placed in the test chamber. A FT cycle comprised a $2 \mathrm{~h}$ cooling and $1 \mathrm{~h}$ heating period. The air in the chamber was maintained at $-20^{\circ} \mathrm{C}$ during the cooling period, and the water in the chamber was maintained at $10{ }^{\circ} \mathrm{C}$ during the heating period.

\section{Results}

\subsection{Material Properties}

The measured values of $\lambda, \lambda^{\prime}$, and $D$ are shown in Table 1 , and the AIs are presented in Fig. 3 . Herein, $\lambda$ was averaged using the results from the three measurement areas, and the values of $\lambda^{\prime}, D$, and the AIs are the results obtained on single specimens. The range of the specimens' surface temperature during the $\lambda$ measurement is also provided in Table 1.

As shown in Table 1, the $\lambda$ of wet samples was 2 to 3 times higher than that of dry samples. The $\lambda$ of T11 was 1.6 and 1.2 times higher than that of T10 in dry and wet states, respectively; In the wet state, the values of T10 and T11 were closer. Notably, the water content of T10 and T11 in the wet state in the $\lambda$ measurements was 271 and $161\left[\mathrm{~kg} / \mathrm{m}^{3}\right]$, respectively. The average temperature and $\mathrm{RH}$ in the test chamber during the $\lambda$ ' measurements were $25.1^{\circ} \mathrm{C}$ and $52.2 \%$, respectively. The value of $\lambda$ ' in the hygroscopic region of T10 was greater than that of T11 (Table 1). The $A$ values of T10 and T11 were 0.127 and $0.106\left[\mathrm{~kg} /\left(\mathrm{m}^{2} \cdot \mathrm{s}^{1 / 2}\right)\right]$, respectively. Although T10 exhibited a slightly larger $A$ than T11, the $D$ of T11 was much larger than that of T10 owing to its lower $w_{c}$ (Eq. (1)).

The highest RH observed during the AI measurements using T10 and T11 was $98.03 \%$ and $99.27 \%$, respectively. According to Fig. 3, T10 adsorbed 9-10 times more water vapor 
than $\mathrm{T} 11$ under $80 \% \mathrm{RH}$, which was expected owing to the larger volume of narrower pores present in T10 compared to that in T11. This trend increased with increasing RH.

The average values of $\sigma$ and $K_{I C}$ are shown in Table 2. For the $K_{I C}$ measurements, one of the five air-dried T10 and T11 specimens broke at a location other than the notch; the results from those samples were excluded. The $\sigma$ and $K_{I C}$ in the wet state were smaller than those in the dry state.

(a)

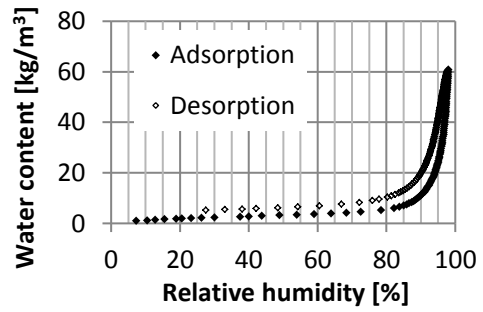

(b)

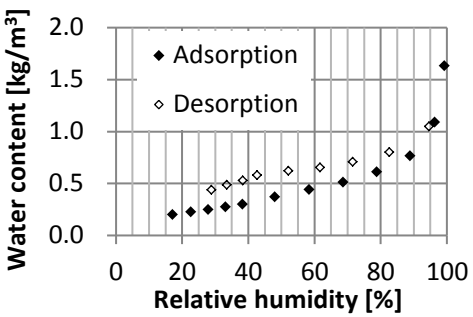

Fig. 3. Adsorption isotherms of samples $\mathrm{T} 10$ (a) and $\mathrm{T} 11$ (b).

Table 1. Thermal and moisture properties of samples T10 and T11.

\begin{tabular}{c|c|c|c|c}
\hline & \multicolumn{2}{|c|}{ Thermal conductivity $[\mathbf{W} /(\mathbf{m} \cdot \mathbf{K})]$} & $\begin{array}{c}\text { Vapor permeability } \\
{[\mathbf{k g} /(\mathbf{m} \cdot \mathbf{s} \cdot \mathbf{P a})]}\end{array}$ & $\begin{array}{c}\text { Moisture diffusivity } \\
{\left[\mathbf{m}^{2} / \mathbf{s}\right]}\end{array}$ \\
\cline { 2 - 3 } & dry & wet & $8.26 \times 10^{-12}$ & $1.95 \times 10^{-7}$ \\
\hline T10 & $0.55\left(23-28^{\circ} \mathrm{C}\right)$ & $1.69\left(23-29^{\circ} \mathrm{C}\right)$ & $4.46 \times 10^{-12}$ & $3.01 \times 10^{-7}$ \\
\hline T11 & $0.89\left(23-27^{\circ} \mathrm{C}\right)$ & $1.99\left(23-27^{\circ} \mathrm{C}\right)$ & 4.46 & \\
\hline
\end{tabular}

Table 2. Mechanical properties of samples T10 and T11.

\begin{tabular}{c|c|c|c|c}
\hline & \multicolumn{2}{|c|}{ Tensile strength [MPa] } & \multicolumn{2}{c}{ Stress intensity factor $\left[\mathbf{M P a} \cdot \mathbf{m}^{\mathbf{1 / 2}}\right]$} \\
\cline { 2 - 5 } & dry & wet & dry & wet \\
\hline T10 & 2.89 & 2.15 & 1.76 & 1.69 \\
\hline T11 & 4.71 & 3.77 & 2.76 & 2.54 \\
\hline
\end{tabular}

\subsection{Freeze-Thaw Test}

Delamination cracks were observed on the side surfaces of T10 after 27 cycles. The cracks expanded after 35 cycles (Fig. 4a); subsequently, T10 was removed from the test chamber. Conversely, no signs of deterioration were found in T11 even after 200 cycles (Fig. 4b).

(a)

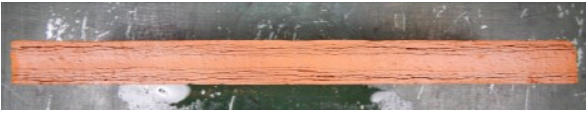

(b)

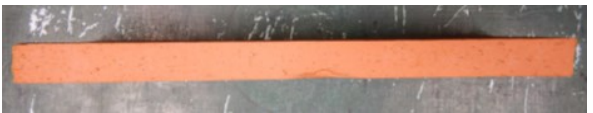

Fig. 4. Side surfaces of T10 after 35 FT cycles (a) and T11 after 203 FT cycles (b).

\section{Discussion}

Based on several FT tests in the literature, Maage [1] concluded that the frost resistance of bricks decreases when the bricks' porosity and percentage of pores with diameters smaller than $3 \mu \mathrm{m}$ are large. Therefore, the lower frost resistance of T10 in the FT test can be explained by the porosity $\left(\approx w_{v}\right)$ and pore size distribution (Fig. 1). The lower $\sigma$ and $K_{I C}$ of T10 may also contribute to its lower frost resistance in the FT test.

Under real weather conditions, hygrothermal properties as well as mechanical properties should be considered because they significantly affect the distribution of temperature and water content in the materials and the frost damage risk as follows:

- The larger $A$ of T10 may either increase or decrease the damage due to frost action. 
While T10 will draw more water, such as continuous rain or groundwater, and easily reach a "critical degree of saturation" [17], the lower $A$ of T11 may prevent the infiltration of water inside the material, thus forcing water to concentrate in the vicinity of the surface (in the case of intermittent water supply to the surface), resulting in more serious damage near the surface.

- As shown in Table 1 , in the wet state, the $\lambda$ of T10 and T11 is more similar than that measured in dry samples because T10 contains more water. When the materials freeze, the magnitude relation may be reversed because of the high thermal conductivity of ice.

- As shown in Fig. 1, because the majority of pores in T11 are wider than those in T10, pore water freezes closer to $0{ }^{\circ} \mathrm{C}$ in $\mathrm{T} 11$ than it does in $\mathrm{T} 10$. Therefore, in relatively warm regions where the temperature drops below $0{ }^{\circ} \mathrm{C}$ only a few times a year, T11 may be subjected to more FT cycles than T10.

- As shown in Table 1 , the $\sigma$ and $K_{I C}$ depend on water content. Therefore, the distribution of the mechanical properties as well as that of temperature and water content should be considered.

\section{Conclusion}

In this study, the thermal, moisture, and mechanical properties of dry and wet fired clay materials were measured, and FT tests were conducted. The frost resistance exhibited in the FT test can be explained by the pore structure and mechanical properties. Finally, the frost damage risk under real weathering conditions was assessed based on the measured hygrothermal properties and their dependency on water content. Further studies should be conducted to confirm these assessments using numerical analysis.

This work was supported by JSPS KAKENHI Grant Number JP17K06641. The authors would like to thank Enago (www.enago.jp) for English language review.

\section{References}

1. M. Maage, Mater. Struct. 17, 345-50 (1984)

2. K. Elert et al., J. Cult. Herit. 4, 91-99 (2003)

3. M. Radeka et al., Ind. Ceram. 30, 97-104 (2010)

4. J. Ranogajec et al., J. Mater. Civ. Eng. 24, 1254-60 (2012)

5. G. Wardeh, B. Perrin, Constr. Build. Mater. 22, 820-28 (2008)

6. C. Iba, A. Ueda, S. Hokoi, Struct. Sur. 34, 135-49 (2016)

7. J. García Ten et al., Ceram. Int. 36, 1951-59 (2010)

8. S.N. Monteiro, C.M.F. Vieira, Appl. Clay Sci. 27, 229-34 (2004)

9. S. Karaman, S. Ersahin, H. Gunal, J. Sci. Ind. Res. 65, 153-59 (2006)

10. I. Johari et al., Sci. Sinter. 42, 245-54 (2010)

11. S. Karaman, H. Gunal, S. Ersahin, Constr. Build. Mater. 20, 348-54 (2006)

12. M. Brun et al., Thermochim. Acta. 21, 59-88 (1977)

13. ISO 8894-2:2007, Refractory materials--Determination of thermal conductivity--Part 2: Hot-wire method (parallel) (2007)

14. M.K. Kumaran, J. Therm. Env. Build. Sci. 22, 349-55 (1999)

15. JIS R 1668, Testing method for fracture toughness of porous fine ceramics (2005)

16. ASTM C 666, Standard test method for resistance of concrete to rapid freezing and thawing (2015)

17. G. Fagerlund, Critical degrees of saturation at freezing of porous and brittle materials. Lund University, Lund (1973) 